\title{
Does it pay to break male gender stereotypes in advertising? A comparison of advertisement effectiveness between the United Kingdom, Poland and South Africa
}

\author{
Magdalena Zawisza ${ }^{a}$, Russell Luyt ${ }^{\mathrm{b}}$, Anna Maria Zawadzka ${ }^{\mathrm{c}}$ and Jacek Buczny ${ }^{\mathrm{d}}$ \\ ${ }^{a}$ department of Psychology, anglia ruskin university, Cambridge, uK; bdepartment of Psychology, university \\ of Greenwich, london, uK; 'department of Psychology, university of Gdańsk, Gdańsk, Poland; department of \\ Psychology, university of Social Sciences and Humanities, Sopot, Poland
}

\begin{abstract}
Advertisers shy away from using non-traditional (vs. traditional) male gender portrayals even though theory suggests they may be more effective cross- nationally. Two main hypotheses were tested cross-nationally for the first time. H1: 'paternalistic' male stereotypes (e.g. Househusband) would be more effective than 'envious' male stereotypes (e.g. Businessman) across countries confirming the stereotype content model (SCM). H2: the match between initial male gender role attitudes and advertisement type would increase advertisement effectiveness only in countries with relatively low egalitarian norms (i.e. Poland and South Africa). A cross-national study was conducted through the use of student samples following a 3(country: United Kingdom, Poland and South Africa) $\times$ 2(advertisement type) $\times$ (gender attitude) mixed design $(\mathrm{N}=373)$. A three-way multivariate analysis of variance showed support for H1 and partial support for H2 (i.e. the second hypothesis held on purchase intent and for South Africa). The study provides evidence for the cross-national applicability of the SCM to advertising and the limited predictive value of gender attitudes for purchase intent depending on country. Thus, contrary to mainstream advertising practices, breaking male gender stereotypes does appear to pay cross-nationally. Theoretical and practical implications alongside the potential for change in practices are discussed.KEYWORDS advertising; gender attitudes; gender portrayal; gender stereotypes; sex roles; cross-cultural
\end{abstract}


Debate concerning the effectiveness of advertisements that either use traditional or non-traditional gender roles is not new (Eisend, 2010; Eisend, Plagemann, \& Sollwedel, 2014; Wolin, 2003). Yet most investigations to date have focused primarily on female gender roles and have used female samples (Orth \& Holancova, 2004). They have also often returned inconsistent findings (Zawisza \& Cinnirella, 2010) and leave two particular questions unanswered: are traditional or non-traditional gender portrayals more effective and are related preferences influenced by pre-existing gender attitudes? This paper incorporates theorizing concerning (gender) stereotypes proposed by Fiske, Cuddy, Glick, and Xu (2002)the stereotype content model (SCM) - in order to examine the first question. It is argued here that the effectiveness of gendered portrayals in advertising will depend on the content of the stereotype used rather than, as early theorizing suggested, on whether traditional as opposed to non-traditional gender roles are portrayed (Eagly, Mladinic, \& Otto, 1991; Fiske \& Stevens, 1993). With regard to the second question, as informed by Aversive Racism Theory (Gaertner \& Dovidio, 1986), it is proposed that the extent to which gender attitudes determine the effectiveness of gendered advertisements will depend upon the strength of egalitarian norms operating in each country. In order to test these predictions, three samples from countries that vary in terms of their gender egalitarianism were examined: the United Kingdom, Poland and South Africa (Zawisza, Luyt, \& Zawadzka, 2012). By focusing on male gender roles and attitudes and by testing the two hypotheses cross-nationally, this paper also attempts to address two further gaps in the literature: the lack of research on the effectiveness of male portrayals in advertising and the lack of cross-national research in this area. The two questions that the paper attempts to answer are discussed below.

\section{Are traditional or non-traditional male portrayals more effective in advertising?}

Questions concerning the effectiveness of traditional vs. non-traditional gender role portrayal in advertising have intrigued researchers over the last 25 years (Eisend et al., 2014; Orth \& Holancova, 2004; Wolin, 2003). Studies related to the portrayal of women have reported a variety of findings. This includes, for example, a general preference for non-traditional (e.g. businesswoman) as opposed to traditional gender role portrayal (e.g. housewife) in advertisements (Bellizzi \& Milner, 1991; Jaffe \& Berger, 1994), the equivalent effectiveness of traditional and non-traditional gender role portrayal strategies in advertising (Whipple \& Courtney, 1980), and the greater effectiveness of traditional gender role portrayal (e.g. housewife) in advertisements (Duker \& Tucker, 1977). Literature concerning the use of male gender roles in advertising is more consistent but scarce. We have only been able to identify three experimental studies of this kind. Debevec and Iyer (1986) as well as Garst and Bodenhousen (1997) and Zawisza and Cinirella (2010) indicated the greater effectiveness of men's non-traditional gender role portrayal as an advertising strategy. These findings are seemingly counter-intuitive, given the often observed negative reactions to non-traditional gender role performance, be it among men or women (e.g. Brescoll \& Uhlmann, 2005; Lenton, Sedikides, \& Bruder, 2006; Martin, 1995; O'Brien, Mistry, Hruda, Caldera, \& Huston, 2000; Sandnabba \& Ahlberg, 1999). In the light of such inconclusive findings, a 'return to theory' is necessary.

\section{Theorizing stereotypes: moving towards the stereotype content hypothesis}

Early theorizing concerning gender stereotypes suggested that any departure from traditional gender roles meets with negative responses (Eagly et al., 1991; Fiske \& Stevens, 1993). For example, a survey by Eagly et al. (1991) revealed that a positive general perception of women as pleasant and unobtrusive (i.e. the 'women are wonderful effect') ceases when they assume traditionally masculine gender roles. There is also considerable evidence that men who assume traditionally feminine gender roles are similarly stigmatized or even more so (Brescoll \& Uhlmann, 2005; Lenton et al., 2006; Lipsitz Bem, 2000; Martin, 1995; Sandnabba \& Ahlberg, 1999). Nonetheless, recent research suggests that this might not always be the case, as is well illustrated by Garst and Bodenhousen (1997) in the United States (US). These authors reported a preference for men's androgynous as opposed to traditionally masculine gender 
role portrayal in advertising. Although not discussed in depth, this finding suggests that responses to advertising may be determined more by the content of gender stereotypes, rather than whether these are traditional or not.

This is reflected in theoretical developments that critically consider the nature of stereotypes. Emphasis is placed on the characteristics of stereotype content rather than merely the extent to which they may be considered traditional. Fiske et al's (2002) SCM suggests that 'competence'(C) and 'warmth' (W) are core dimensions underlying social stereotypes. On the basis of these dimensions, stereotypes may be categorized as one of four types: 'paternalistic' (low C and high W), 'envious' (high C and low W), 'admiration' (high $\mathrm{C}$ and high W) and 'contemptuous' (low C and low W). It is noteworthy that 'envious' stereotypes trigger respect but not liking, whilst'paternalistic' stereotypes trigger liking but not respect (Fiske et al., 2002; Fiske, Xu, Cuddy, \& Glick, 1999; Judd, James-Hawkins, Yzerbyt, \& Kashima, 2006; US samples). SCM principles are applicable to stereotypes across different social categories (Fiske et al., 2002), including gender (Eckes, 2002). Eckes (2002), for instance, found that 'businessman' and 'businesswoman' types are perceived as 'envious', whereas the 'housewife' type is viewed as 'paternalistic'. They have also been shown to apply to consumer context (Kervyn, Fiske, \& Malone, 2012; Zawisza \& Pittard, 2015).

In addition to the observation that 'paternalistic' stereotypes are liked to a greater extent than those that are categorized as 'envious', liking of advertising also appears as one of the most important determinants of their effectiveness (Du Plessis, 2005). This has proven applicable to gendered advertising (Infanger \& Sczesny, 2015; Zawisza \& Cinnirella, 2010). Moreover, 'warmth' is afforded primacy over 'competence', such that warmth influences affective and behavioural judgements to a greater extent than competence (Fiske, Cuddy, \& Glick, 2006). This informs the stereotype content hypothesis: men's traditional but 'envious' gender role portrayal (e.g. Businessman) will be less effective in advertising than the non-traditional 'paternalistic' type (e.g. Househusband). Previous research provides support for this hypothesis (Zawisza \& Cinnirella, 2010). The present paper attempts to replicate this finding through examining a sample from the United Kingdom and then testing its generalizability to Polish and South African samples. Whether or not this hypothesis holds cross-nationally remains, as of yet, empirically unexamined. We address this below.

\section{Stereotype content cross-nationally: moving towards the stereotype similarity hypothesis}

Cross-national comparisons offer more evidence for similarities than differences in gender stereotypes between countries. For example, Williams and Best (1982, 1990) measured gender stereotypes in 25 countries through the use of the Adjective Check List. They reported that people of varying social status and from across different nations perceived women as interpersonally oriented, passive and weak. In comparison, men were seen as instrumentally oriented, assertive, active and strong. Williams, Satterwhite, and Best (1999) provide similar findings. The SCM has also been shown to generalize across different social groups, including the perception of Asian-Americans (Lin, Kwan, Cheung, \& Fiske, 2005), Jews (Glick, 2002), the elderly (Cuddy, Norton, \& Fiske, 2005), as well as Black and gay people (Fiske et al., 2002). It also generalizes across 15 European Union nations and 3 Asian countries (Cuddy, Fiske, \& Glick, 2008). All of these studies included the United Kingdom and, in two instances, a South African sample. A Polish sample was not included in any of these studies. Yet additional research suggests the SCMs wide cross-national applicability (Cuddy et al., 2008; Fiske et al., 2006; Judd et al., 2005). On this basis it is predicted that the stereotype content hypothesis, as introduced above, will hold across all three countries. More specifically, the stereotype similarity hypothesis suggests that a preference for 'paternalistic' over 'envious' gender role portrayal strategies in advertising will emerge in the United Kingdom, Poland and South Africa.

The stereotype content and stereotype similarity hypotheses, as described above, contribute towards examining the first research question (i.e. 'Are traditional or non-traditional gender portrayals more effective?'). The second research question (i.e. 'Are patterns of preference influenced by pre-existing gender attitudes?’) is discussed further below. 


\section{Research and theorizing concerning the role of gender attitudes: moving towards the match hypothesis}

It seems reasonable to assume that pre-existing individual gender attitudes might determine the effectiveness of gendered advertisements. But research concerning the role of various gender-related variables (e.g. gender attitudes, ideology, identity and career orientation) in determining the effectiveness of advertising is ambiguous (e.g. Barry, Gilly, \& Doran, 1985; Bellizzi \& Milner, 1991; Debevec \& Iyer, 1986; Duker \& Tucker, 1977; Ford \& Latour, 1993; Garst \& Bodenhausen, 1997; Whipple \& Courtney, 1980; Worth, Smith, \& Mackie, 1992). Palan (2001), Wolin (2003), and Zawisza and Cinnirella (2010) provide useful overviews to this research. Such ambiguity is all the more surprising given firm theoretical arguments in support of the relationship between gender attitudes and the effectiveness of gendered advertisements. For example, Sherif and Hovland's (1961) Social Judgment Theory suggests that persuasive messages that make use of counter-attitudinal appeal risk rejection, which in turn might decrease advertisement effectiveness. This argument is reflected in the match hypothesis proposed here: people with liberal attitudes to male gender roles will prefer advertisements making use of non-traditional gender role portrayal, whilst people with more traditional attitudes to male gender roles will favour advertisements making use of traditional gender role portrayal.

Why then, given the intuitive appeal and theoretical strength of this hypothesis, does it receive inconsistent empirical support? This may be explained, at least partially, in terms of egalitarian norms. The strength of these norms has reportedly increased in society over time and they act to dissuade people from expressing, for example, sexist attitudes (Glick et al., 2004). This poses difficulties in the measurement of attitudes to gender roles, and as a result, their predictive strength for advertisement effectiveness. Many attempts have been made to address this problem through developing new more sensitive measures of sexism - for example the Modern Sexism Scale (Swim, Aikin, Hall, \& Hunter, 1995), Neosexism Scale (Tougas, Brown, Beaton, \& Joly, 1995) and Ambivalent Sexism Inventory and Ambivalence Toward Men Inventory (Glick \& Fiske, 1996, 1999). The extent to which these measures represent a genuine advance is debatable. They all correlate significantly with their predecessors (Swim, Mallet, \& Russo-Devosa, 2005) and it is therefore arguable whether they are indeed more sensitive (Nelson, 2002). Inherent measurement difficulties may alternatively be addressed through accounting for egalitarian norms in research design. The predictive value of gender attitudes might be observed in contexts that differ in the strength to which egalitarian norms are in operation. Thus this paper additionally seeks to investigate the match hypothesis across three national contexts that vary in the strength of their egalitarian norms (Zawisza et al., 2012). We believe that this is the first occasion upon which this has been examined.

\section{Gender attitude-advertisement match cross-nationally: moving towards the attitudinal differences hypothesis}

Unlike cross-national comparison of gender stereotypes, cross-national research concerning gender attitudes offers greater evidence for differences, rather than for similarities between countries. For example, (West) European countries are consistently shown to be more egalitarian than South Africa (SA) and Asian countries (Williams \& Best, 1990). SA ranks among the highest, out of 19 nations, in terms of sexism towards women (Glick et al., 2000). In contrast, the United Kingdom (UK) ranks among the lowest. Among Eastern European countries, Poland is rated as moderately egalitarian in terms of attitudes towards both male and female gender roles (Robila \& Krishnakumar, 2004) and beliefs in gender equality (Olson et al., 2007). Although none of these studies compared PL, SA and the UK directly, they do suggest that SA is more sexist than PL, whilst the UK is more egalitarian than both. A direct comparison of these countries confirming this pattern among student samples was reported by Zawisza et al. (2012). Since research applying AST has shown that ambivalent sexism correlates positively and significantly with social indicators of equality, such as the Gender Empowerment Measure (Glick et al., 2004), it can be argued that the three countries chosen here represent a continuum of gender egalitarianism - PL somewhere between the extremes of SA and the UK. This allows us to examine the influence that egalitarian norms have on the predictive power of gender attitudes in determining the 
effectiveness of gendered advertisements. It is expected here that the strength of egalitarian norms will affect the interaction between advertisement type and gender attitudes.

The first prediction is based on Aversive Racism Theory (Gaertner \& Dovidio, 1986). This argues that aversive racists hold both learnt negative attitudes as well as positive egalitarian beliefs about stigmatized groups. These individuals, therefore, reveal their racist attitudes only when their behaviour may be considered socially acceptable (i.e. attributed to factors other than racist attitudes). There are clear similarities between racism and sexism (Fiske \& Taylor, 1991; Swim et al., 1995; Tougas et al., 1995), which makes it possible to apply this theory to the latter (Petty, Fleming, \& White, 1999). We therefore predict that people with more traditional attitudes to male gender roles will be motivated to appear non-prejudiced, in countries such as the UK with relatively strong egalitarian norms, thereby reducing the predictive strength of gender attitudes. This will not be the case in less egalitarian countries such as Poland and SA where such norms are relatively weaker (Zawisza et al., 2012). Thus, it is expected that the match hypothesis will only apply in countries that are gender-conservative (i.e. Poland and SA) as opposed to those that are egalitarian (i.e. the UK). Cross-national differences will therefore exist concerning the role of gender attitudes in determining the effectiveness of gendered advertisements. These predictions are referred to as the attitudinal differences hypothesis. To the authors' knowledge, no study to date has directly investigated the extent to which the operation of egalitarian norms might have contributed towards contradictory existing research findings. The current paper attempts to address this issue by examining the match hypothesis in three purposively selected countries that differ in their levels of gender egalitarianism (Zawisza et al., 2012). The UK and SA were chosen as they signify the extreme ends of the continuum of egalitarianism (Glick et al., 2004) and Poland was chosen as an under-researched country which is reportedly moderately egalitarian (Zawisza et al., 2012).

In sum, two main hypotheses are proposed: the stereotype content hypothesis (i.e. preference of 'paternalistic' over 'envious' advertisement types) and the match hypothesis (i.e. preference for advertisement strategies that match pre-existing individual gender attitudes). Whilst it is anticipated that the former will hold across countries (i.e. stereotype similarity hypothesis), it is argued here that the latter will hold for gender-conservative countries such as SA and Poland but not for gender-egalitarian countries such as the UK (i.e. attitudinal differences hypothesis).

Research has operationalized the notion of advertisement effectiveness differently (Wolin, 2003; Zawisza \& Cinnirella, 2010). The concepts of advertisement evaluation and purchase intent have featured particularly prominently in these attempts. We have drawn upon this broader literature in order to identify three indicators of advertisement effectiveness in the current study. This includes feelings triggered by the advertisement, judgements about the advertisement, and purchase intent. Since it has been shown that these three types of responses to an advertisement are related (Brown \& Stayman, 1992; Burke \& Edell, 1989), it is expected here that the four predictions should be evident across all three indicators of advertisement effectiveness.

\section{Method}

\section{Participants}

A power analysis was conducted using $\mathrm{G}^{*}$ power for an mixed design multivariate analysis of variance (MANOVA), assuming medium effect size of .25, alpha error probability .05 and interest in interactions (6 groups and 12 measurements) with a standard correlation among repeated measures of .05. This suggested a sample size of 174 . Since, however, we were interested in cross-cultural comparisons, we aimed to obtain a minimum 120 participants per each country in line with the typical standards in cross-cultural research. Our initial total sample size was $n=557$. This was reduced to the final $n=373$ via the median split procedure described later.

\section{British sample}

One hundred and twenty-two participants were recruited from Royal Holloway, University of London, of whom $68 \%$ were women and $32 \%$ men. Their mean age was $20.4(\mathrm{SD}=4.9)$ and ranged from 18 to 
46 years. The majority were studying Psychology (72\%), whilst the remainder took courses in the arts (12\%), science (9\%) and joint programmes $(6 \%)$ or did not report subject studied (1\%). Students were encouraged to participate through campus-wide advertising in which they were offered a chance to enter a prize draw. A first-year undergraduate Participation Scheme also contributed towards participant numbers.

\section{Polish sample}

One hundred and twenty-three Polish participants from Gdansk University, Poland, were tested (82\% women and $18 \%$ of men). The average age was $21.9(\mathrm{SD}=2.44)$, ranging from 19 to 28 years. A majority of the students were recruited from the Psychology department (88\%) and the remaining participants came from arts (1\%), science (4\%) and joint programmes (6\%). One per cent did not report the subject studied. The participants were recruited by announcements distributed on campus and via e-mails. They were offered monetary remuneration for their time.

\section{South African sample}

One hundred and twenty-eight South African participants from the University of Cape Town, South Africa, were tested (57\% women and $43 \%$ of men). The average age was $20.6(\mathrm{SD}=2.4)$, ranging from 18 to 37 years. The majority of the students were recruited from Arts, Psychology and Commerce departments (72\%) and the remaining participants came from the sciences (26.4\%). The participants were recruited by announcements distributed on campus and via e-mail. They were offered monetary remuneration for their time. ${ }^{1}$

\section{Design and procedures}

The experiment used a mixed 3 (country: UK, SA, PL) $\times 2$ (Gender Attitude: Traditional vs. Liberal) between $\times 2$ (Advertisement Type: Traditional vs. Non-traditional) within-subjects design where participants were assigned randomly to the advertisement type condition. A mixed design was adopted as an efficient option which increases the study's power and reduces cost of the cross-national investigation.

Participants were informed that the study examined individual responses to different advertisements. Students participated either individually or in groups up to a maximum of six individuals. Each was provided with a questionnaire booklet including two printed advertisements. These depicted men performing different roles (i.e. traditional and non-traditional). Two versions of the advertisements were progressive (i.e. Househusband: Hh1 and Hh2) and two others were traditional (i.e. Businessman: Bm1 and Bm2). Participants were provided with one of eight possible Househusband and Businessman combinations (e.g. Bm1 and Hh2) achieved via counterbalancing the order in which these were presented. All advertisement were followed by the same set of Likert-type and semantic differential scales and participants were asked to evaluate the advertisements by responding to these. They were then required to complete two gender attitude measures, ostensibly so as to test their measurement validity, as an entirely separate study. All the scales were back-translated by independent translators using standard back-translation techniques (Brislin, 1970). Any ambiguities in the translations were resolved via discussion. Participation took approximately half an hour, after which individuals were fully debriefed.

\section{Independent variables}

Advertisement type. The men portrayed in the two printed advertisements were carefully pre-selected through a separate pilot study (Zawisza, 2006). The 'envious' traditional male role portrayal was perceived as more traditional and less liberal than the 'paternalistic' progressive male role portrayal. Additional manipulation checks are reported below. The characters were also matched in terms of attractiveness ${ }^{2}$. As noted above, two versions of the advertisement depicted progressive portrayals, whilst two depicted traditional portrayals. These were printed and prepared especially for the purpose of the experiment ${ }^{3}$. Orange juice was selected as the advertised product, due to being low-involving and unisex, ${ }^{4}$ and the brands were specifically developed for the current study to control for familiarity and marketing effects (i.e. brand ' $\mathrm{X}$ ' for the traditional advertisement and ' $\mathrm{Y}$ ' for the non-traditional one). 
Attitudes to male gender roles. Two attitudinal measures of male gender roles were used. The Attitudes to Men Scale (AMS; Falkenberg, Hindman, \& Masey, 1983) consists of 14 items concerning the rights and roles of men in society. Participants were asked to express their attitudes on a five-point response format that ranges from 1 (Agree strongly) to 5 (Disagree strongly). A higher score indicates more liberal attitudes towards male roles. Validity evidence in support of this scale's use is good as reported in Falkenberg et al. (1983). Glick and Fiske's (1999) Ambivalent Toward Men Inventory (AMI) was also included (Glick \& Fiske, 1999; Glick et al., 2004) to allow, in combination with AMS, for more accurate identification of gender attitudes in the samples (see below). AMI contains 20 items assessing sexist attitudes towards men. Participants are asked to express their attitudes on a six-point response format in which the higher the general score the more sexist the individual. The scale's predictive, convergent and discriminant validity is reported in Glick and Fiske (1999). Zawisza et al. (2012) also confirm the invariance of this measure on Polish, British and South African student samples.

\section{Dependent variables}

Purchase intent. A declarative purchase intent likelihood scale (0-100\%) was included. This required participants to indicate the probability that they would buy the advertised product.

Feelings triggered by the advertisement. The Feelings Scale (Burke \& Edell, 1989), which was developed and validated in an advertising context, was used. In order to reduce fatigue only 21 out of the original 56 items were selected on the basis of a factor loading of $>.70$. Participants were asked to indicate on a seven-point response format, ranging from 1 (Not at all) to 7 (Verystrongly), to what extent the relevant feeling (e.g. happy, delighted, sentimental, moved, sceptical, offended) was evoked when viewing the advertisement.

Judgements about the advertisement. The Judgements Scale (Burke \&Edell, 1989), which was also developed and validated in an advertising context, was used. Again, in order to reduce fatigue only 16 out of the original 25 items were selected on the basis of a factor loading of $>.70$. Participants were asked to indicate on a seven-point response format, ranging from 1 (Not at all well) to 7 (Extremely well), how well they thought each relevant word (e.g. irritating, interesting, imaginative, ingenious, soothing, gentle) described the viewed advertisement.

Manipulation checks. In order to determine whether the chosen depictions of men had the anticipated impact on participants, two additional items were included in the Judgements Scale. Participants were asked to indicate on a seven-point response format, ranging from 1 (Not at all) to 7 (Extremely well), how well the adjectives 'liberal' and 'traditional' described the advertisements.

\section{Results}

\section{Preliminary analyses}

\section{Manipulation checks}

Two-item manipulation checks were also included in the main analysis allowing for between country comparisons concerning the perception of advertisements as 'liberal' and 'traditional'. A 2(advertisement type) $\times 3$ (country) MANOVA revealed the expected significant main effect of advertisement type as well as a significant effect of country. The multivariate test statistic using Pillai's trace were as follows: $V=.19$, $F(2,360)=21.57, p<.001,{ }_{\mathrm{p}}^{2}=.194$ (a large effect) - for advertisement type; $V=.19, F(4,720)=9.75$, $p<.001, \underset{\mathrm{p}}{2}=.198$ (a large effect) - for country and $V=.024, F(4,720)=1.114$, ns. - for country $\times$ advertisement type. Separate univariate ANOVAs revealed the same significant main effects for both of the outcome variables: for 'liberal' $M_{\mathrm{Hh}}=3.6, \mathrm{SD}=.095$ vs. $M_{\mathrm{Bm}}=2.72, \mathrm{SD}=.078, F(1,362)=66.33$, $p>.001,{ }_{\mathrm{p}}^{2}=.155$ (a large effect), and for 'traditional' $M_{\mathrm{Hh}}=2.77, \mathrm{SD}=.094 \mathrm{vs.} M_{\mathrm{Bm}}=3.29, \mathrm{SD}=.10, F(1$, $362)=17.765, p>.001, \underset{\mathrm{p}}{2}=.047$ (a medium effect). This indicates that irrespective of country the $\mathrm{Bm}$ advertisements were seen as significantly more traditional and less liberal than the Hhadvertisements. 
The univariate main country effects showed that both advertisement types were also perceived as significantly more liberal in $\mathrm{PL}(M=3.42, \mathrm{SD}=.11)$ than in the $\mathrm{UK}(M=2.97, \mathrm{SD}=.12)$ or SA $(M=3.10$, $\mathrm{SD}=.12), F(2,362)=4.197, p<.01, \mathrm{p}=.023$ (a relatively small effect), and marginally less traditional in Table 1. Cronbach's alpha coefficients per country for the scales used.

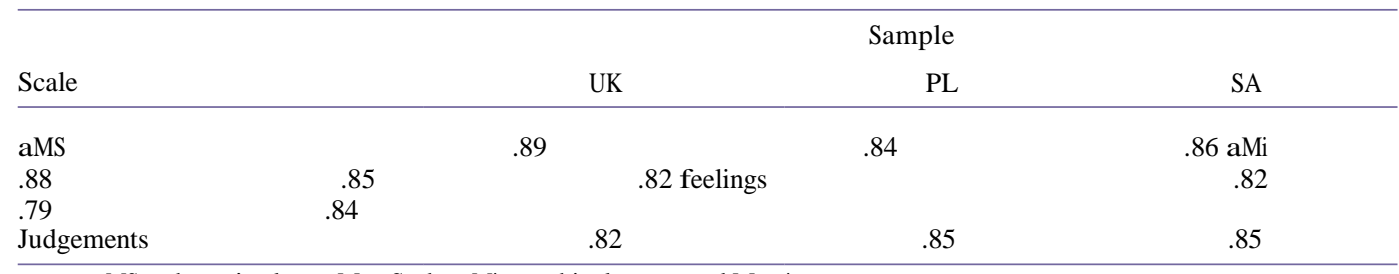

notes: aMS - the attitudes to Men Scale, aMi - ambivalent toward Men inventory.

the $\mathrm{UK}(M=2.77, \mathrm{SD}=.13)$ than in $\mathrm{PL}(M=3.12, \mathrm{SD}=.13)$ or $\mathrm{SA}(M=3.19, \mathrm{SD}=.14), F(2,362)=2.875$, $p=.058, \underset{\mathrm{p}}{2}=.016$ (a small effect).

Reliability. Cronbach's alpha coefficients indicated good reliability for all scales across all samples (see Table 1).

Median splits. Median splits were used to divide participants into groups (Iacobucci, Posovac, Kardes, Schneider, \& Popovich, 2015) in the case of the AMS [i.e. Traditional $(<54)$ and Liberal $(\geq 54)$ ] and the AMI [i.e. Non-sexists $(\leq 43)$ and Sexist $(>43)$ ]. AMS groups differed significantly (two-tailed, independent $t$ tests) in their attitudes in each country: in the UK $t(212)=23.787, p<.001, d=3.26\left(M_{\mathrm{Tr}}=2.96\right.$, SD $=.38$ vs. $\left.M_{\mathrm{Lib}}=4.23, \mathrm{SD}=.40\right)$, in PL $t(188.003)=19.716, p<.001, d=2.86,\left(M_{\mathrm{Tr}}=2.63, \mathrm{SD}=.36\right.$ vs. $M_{\mathrm{Lib}}$ $=3.77, \mathrm{SD}=.44)$; and in SA $t(188)=20.466, p<.001, d=3.02,\left(M_{\mathrm{Tr}}=2.66, \mathrm{SD}=.33 \mathrm{vs} . M_{\mathrm{Lib}}=3.81, \mathrm{SD}=\right.$ .43). They also differed significantly in their attitudes, with respect to the AMI, in each country: in the UK $t(193.43)=20.381, p<.001, d=-2.82\left(M_{\text {sex }}=2.71, \mathrm{SD}=.40\right.$ vs. $\left.M_{\text {nsex }}=1.43, \mathrm{SD}=.51\right)$, in PL $t(152.455)=18.828, p<.001, d=-2.81\left(M_{\text {sex }}=2.91, \mathrm{SD}=.35\right.$ vs. $\left.M_{\text {nsex }}=1.78, \mathrm{SD}=.46\right)$; and in SA $t(166.69)=19.283, p<.001, d=-2.83\left(M_{\text {sex }}=3.12, \mathrm{SD}=.39\right.$ vs. $\left.M_{\mathrm{nsex}}=1.86, \mathrm{SD}=.50\right)$. As indicated by the Cohen's $d$ statistics, all of these effects were large. Only participants scoring consistently on both scales were entered into further analyses. This procedure resulted in a sample reduction to $n=373$ (from $n=557$ ).

\section{Main analysis}

In order to avoid Type I error, MANOVA was conducted by country, advertisement type and gender attitudes for all measures of advertising effectiveness (Feelings, Judgements and Purchase Intent). Table 2 provides a summary of descriptive statistics and Table 3 of inferential statistics. For ease of reading, only significant findings are reported below. For non-significant statistic refer to Table 3. Our main analysis aimed to test: (a) the stereotype content hypothesis with main advertisement type effects; (b) the stereotype similarity hypothesis with an advertisement type $\times$ country interaction; (c) the match hypotheses with advertisement type $\times$ gender attitude interaction effects; and (d) the attitudinal differences hypothesis with an advertisement type $\times$ gender attitude $\times$ country interaction effect.

The multivariate test statistic using Pillai's trace indicated that there were significant main effects of country, $V=.09, F(6,742)=5.86, p<.001,{ }_{\mathrm{p}}^{2}=.045$ (a medium effect) and of advertisement type, $V=.193, F(3,370)=29.50, p<.001,{ }_{\mathrm{p}}^{2}=.193$ (a large effect). There were also notable interaction effects between advertisement type $\times$ gender attitudes, $V=.020, F(3,370)=2.57, p=.054,{ }_{\mathrm{p}}^{2}=.020$ (a small effect) and a three-way interaction effect, $V=.042, F(6,742)=2.63, p<.01,{ }_{\mathrm{p}}^{2}=.021$ (a small effect). The advertisement type $\times$ country effect was ns (see Table 3 ). Separate univariate ANOVAs on the specific outcome variables are reported below in an order consistent with the hypotheses. 


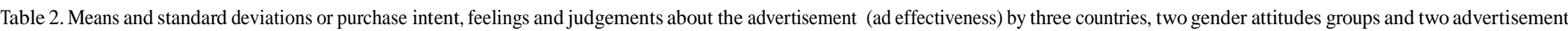
types.

\begin{tabular}{|c|c|c|c|c|c|c|c|c|c|c|c|c|c|c|c|c|c|c|c|}
\hline \multirow[b]{3}{*}{ Measure } & \multirow{3}{*}{$\begin{array}{c}\text { Country } \\
\text { GA } \\
\text { AT }\end{array}$} & \multicolumn{2}{|c|}{ UK } & \multicolumn{4}{|c|}{ PL } & \multicolumn{2}{|c|}{ SA } & \multicolumn{4}{|c|}{ UK } & \multicolumn{2}{|c|}{ PL } & \multicolumn{4}{|c|}{ SA } \\
\hline & & \multicolumn{10}{|c|}{ Liberal } & \multicolumn{8}{|c|}{ Traditional } \\
\hline & & $M$ & SD & $N$ & $M$ & SD & $N$ & $M$ & SD & $N$ & $M$ & SD & $N$ & $M$ & SD & $N$ & $M$ & SD & $N$ \\
\hline \multirow[t]{2}{*}{$\overline{\mathrm{Pi}}$} & $\mathrm{Hh}$ & 3.38 & 2.34 & 64 & 4.56 & 1.96 & 66 & 4.97 & 2.74 & 59 & 3.98 & 2.74 & 57 & 5.13 & 2.34 & 69 & 4.08 & 2.70 & 63 \\
\hline & $\mathrm{Bm}$ & 3.02 & 2.57 & 64 & 4.77 & 2.33 & 66 & 4.39 & 2.83 & 59 & 3.56 & 2.41 & 57 & 4.36 & 2.38 & 69 & 4.92 & 2.54 & 63 \\
\hline \multirow[t]{2}{*}{$\mathrm{f}$} & $\mathrm{Hh}$ & 2.85 & .76 & 64 & 3.11 & .65 & 66 & 3.04 & .89 & 59 & 2.91 & .98 & 57 & 3.04 & .85 & 69 & 3.06 & .89 & 63 \\
\hline & $\mathrm{Bm}$ & 2.71 & .76 & 64 & 2.75 & .58 & 66 & 2.61 & .76 & 59 & 2.80 & .73 & 57 & 2.85 & .88 & 69 & 2.95 & .99 & 63 \\
\hline \multirow[t]{2}{*}{$\mathrm{J}$} & $\mathrm{Hh}$ & 3.08 & .68 & 64 & 3.48 & .75 & 66 & 3.33 & .96 & 59 & 3.17 & .84 & 57 & 3.32 & .94 & 69 & 3.44 & .86 & 63 \\
\hline & $\mathrm{Bm}$ & 2.74 & .72 & 64 & 2.87 & .71 & 66 & 2.88 & .84 & 59 & 2.77 & .71 & 57 & 3 & .90 & 69 & 3.32 & .95 & 63 \\
\hline
\end{tabular}

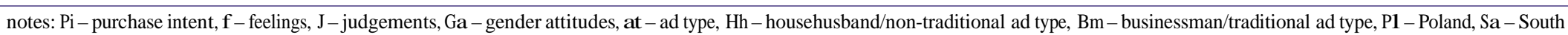
africa, uK - united Kingdom. 
Table 3. results of analysis of variance for country, advertisement type and gender attitudes on purchase intent, feelings and judgements about the advertisements (ad effectiveness).

\begin{tabular}{|c|c|c|c|c|c|c|c|}
\hline Variable & Measure & df (372) & SS & MS & $F$ & $p$ & 2 \\
\hline \multicolumn{8}{|l|}{ Within subjects } \\
\hline \multirow[t]{3}{*}{ ad type (at) } & $\mathrm{Pi}$ & 1 & 6.002 & 6.002 & 1.28 & ns & .003 \\
\hline & $\mathrm{f}$ & 1 & 9.25 & 9.25 & 33.53 & .000 & .08 \\
\hline & $\mathrm{J}$ & 1 & 25.93 & 25.93 & 81.46 & .000 & .18 \\
\hline \multirow[t]{3}{*}{ ad type $($ at $) \times$ Gender attitude $(\mathrm{Ga})$} & $\mathrm{Pi}$ & 1 & .74 & .74 & .16 & ns & .001 \\
\hline & $\mathrm{f}$ & 1 & 1.50 & 1.50 & 5.44 & .02 & .01 \\
\hline & $\mathrm{J}$ & 1 & 1.70 & 1.70 & 5.34 & .02 & .01 \\
\hline \multirow[t]{3}{*}{ ad type $($ at $) \times$ Country $(C)$} & $\mathrm{Pi}$ & 2 & 9.26 & 4.63 & .99 & ns & .005 \\
\hline & $\mathrm{f}$ & 2 & .93 & .47 & 1.69 & ns & .009 \\
\hline & $\mathrm{J}$ & 2 & 1.02 & .51 & 1.60 & ns & .009 \\
\hline \multirow[t]{3}{*}{ at $\times \mathrm{Ga} \times \mathrm{C}$} & $\mathrm{Pi}$ & 2 & 46.51 & 23.26 & 4.97 & .007 & .03 \\
\hline & $\mathrm{f}$ & 2 & .64 & .32 & 1.17 & ns & .006 \\
\hline & $\mathrm{J}$ & 2 & 1.50 & .75 & 2.36 & .10 & .01 \\
\hline \multicolumn{8}{|l|}{ Between subjects } \\
\hline \multirow[t]{3}{*}{ Gender attitude (Ga) } & $\mathrm{Pi}$ & 1 & 4.79 & 4.79 & .62 & ns & .002 \\
\hline & $\mathrm{f}$ & 1 & 1.56 & 1.56 & 1.55 & ns & .004 \\
\hline & $\mathrm{J}$ & 1 & 2.27 & 2.72 & 2.16 & ns & .006 \\
\hline \multirow[t]{3}{*}{ Country (C) } & $\mathrm{Pi}$ & 2 & 225.33 & 112.66 & 14.59 & .000 & .07 \\
\hline & $\mathrm{f}$ & 2 & 2.02 & 1.00 & 1.00 & ns & .005 \\
\hline & $\mathrm{J}$ & 2 & 12.42 & 6.21 & 5.90 & .003 & .03 \\
\hline \multirow{3}{*}{$\mathrm{Ga} \times \mathrm{C}$} & $\mathrm{Pi}$ & 2 & 17.86 & 8.93 & 1.16 & ns & .006 \\
\hline & $\mathrm{f}$ & 2 & .925 & .46 & .46 & ns & .002 \\
\hline & $\mathrm{J}$ & 2 & 2.67 & 1.34 & 1.27 & ns & .007 \\
\hline
\end{tabular}

notes: SS - sum of squares, MS - mean square, df - degrees of freedom, Pi - purchase intent, $\mathrm{f}$ - feelings, $\mathrm{J}$ - judgements, ns non-significant.

\section{Testing stereotype content and stereotype similarity hypotheses}

Main advertisement type effects congruent with the stereotype content and stereotype similarity hypotheses emerged on both the Feelings, $F(1,372)=33.53, p<.001,{ }_{\mathrm{p}}^{2}=.083$ (a medium effect), and Judgements, $F(1,372)=81.46 ; p<.001,{ }_{\mathrm{p}}^{2}=.18$ (a large effect). 'Paternalistic' male portrayal (Hh advertisements) evoked more positive feelings $(M=3.00, \mathrm{SD}=.04)$ and judgements $(M=3.30, \mathrm{SD}=.04)$ than 'envious' male portrayal (Bm advertisements; $M=2.78, \mathrm{SD}=.04$ and $M=2.93, \mathrm{SD}=.04$, respectively). As indicated above, the advertisement type $\times$ country effect was ns implying that this preference indeed held irrespective of country.

\section{Testing the match and attitudinal differences hypotheses}

The significant advertisement type $\times$ gender attitude interaction effect was evidenced on both feelings, $F(1,372)=1.50, p=.020, \quad{ }_{\mathrm{p}}^{2}=.014$, and judgements, $F(1,372)=5.34, p=.021,{ }_{\mathrm{p}}^{2}=.014$ (both effects were small). Follow up analyses with Bonferroni corrected $(p=.0125)$ independent $t$ tests (two-tailed) revealed that overall Liberals' feelings and judgements were significantly more positive in response to the Househusband advertisement type $\left(M_{\mathrm{f}}=3.0, \mathrm{SD}=.78\right.$ and $\left.M_{\mathrm{j}}=3.30, \mathrm{SD}=.81\right)$ than to the Businessman advertisement type $\left(M_{\mathrm{f}}=2.69, \mathrm{SD}=.81\right.$ and $\left.M_{\mathrm{j}}=2.83, \mathrm{SD}=.76\right): t(188)=5.529, p<.001$, $d=.40^{5}$ for feelings and $t(188)=8.186, p<.001, d=.60$ for judgements (both effects were of medium in size). Gender conservative individuals similarly reported significantly more positive feelings and judgements to the Househusband advertisement type $\left(M_{\mathrm{f}}=3.01, \mathrm{SD}=.84\right.$ and $\left.M_{\mathrm{j}}=3.32, \mathrm{SD}=.88\right)$ than to the Businessman advertisement type $\left(M_{\mathrm{f}}=2.87, \mathrm{SD}=.88\right.$ and $\left.M_{\mathrm{j}}=3.04, \mathrm{SD}=.89\right)$ and these differences were significant too: dependent, two-tailed $t(189)=2.643, p=.009, d=.19$ (a small effect) for feelings and $t(189)=4.700, p<.001, d=.34$ (a medium effect) for judgements. Given the Bonferroni correction, there was also a tendency towards significance such that the Businessman advertisement type triggered somewhat more positive feelings in Conservative people $(M=2.87$, SD $=.87)$ than in Liberals $(M=2.69, \mathrm{SD}=.70)$, independent two-tailed $t(360.645)=2.168, p=.031, d=-.22$ (a small effect). 
The same pattern emerged for judgements. Specifically, there was a tendency for Conservatives to judge the Bm advertisement more positively $(M=3.04$, SD $=.89)$ than Liberals $(M=2.82$, SD $=.76)$, independent two-tailed $t(377)=2.493, p=.013, d=-.26$ (a small effect). Overall this pattern partially confirms the match hypothesis. Liberals responded more positively to the Househusband vs. the Businessman) advertisement. They were less positive than Traditionals to the Businessman advertisement. Moreover, they did not differ from Traditionals in their evaluation of the Househusband advertisement. Traditionals on the other hand still liked the Househusband advertisement more than the Businessman advertisement. Since, a three-way interaction by country did not emerge for judgements and feelings, these effects do not offer support for the attitudinal differences hypothesis. Such an interaction did, however, emerge for purchase intent as reported below.

Examination of the univariate tests revealed that the three-way interaction reached significance for Purchase Intent only, $F(2,372)=2.36, p=.007,{ }_{\mathrm{p}}^{2}=.026$ (a small effect). To test the match and attitudinal differences hypotheses this three-way interaction was followed up systematically by running an advertisement type $\times$ gender attitude ANOVAs for each country separately. While none of the main and interaction effects were significant in the UK, the interaction effect reached significance in both Poland, $F(1,133)=4.06, p=.046, \stackrel{2}{\mathrm{p}}=.030$ (a small effect), and South Africa, $F(1,120)=5.70, p=.019$, ${ }_{\mathrm{p}}^{2}=.045$ (a medium effect). Further follow up paired, two-tailed, $t$ tests (Bonferroni corrected at $p=.0125$ ) revealed that in Poland there was a tendency for Conservatives to have higher purchase intent for the Househusband advertisement type $(M=5.13, \mathrm{SD}=2.34)$ than for the Businessman advertisement type $(M=4.36, \mathrm{SD}=2.37), t(68)=2.089, p=.040, d=.25$ (a small effect). In South Africa on the other hand there was a tendency for the Conservatives to report higher purchase intent for the Businessman advertisement type $(M=4.92, \mathrm{SD}=2.54)$ than for the Househusband advertisement type $(M=4.07$, $\mathrm{SD}=2.70), t(62)=1.998, p=.050, d=-.252$ (a small effect). Thus the pattern of findings on purchase intent supports the match hypothesis partially as the findings align in the expected direction in SA but not in PL. The attitudinal differences hypothesis received some support too: gender attitudes played role in determining purchase intent in the less egalitarian countries (PL and SA), but not in the UK.

\section{Additional effects}

While the main country effect was not predicted, the univariate analyses revealed that it was significant for judgements, $F(2,372)=5.89, p=.003,{ }_{p}^{2}=.031$ (a small effect), and for purchase intent, $F(2$, $372)=14.59, p<.001,{ }_{p}^{2}=.073$ (a medium effect). In both cases the British sample responded less positively $\left(M_{\mathrm{j}}=2.94, \mathrm{SD}=.07\right.$ and $\left.M_{\mathrm{pi}}=3.48, \mathrm{SD}=.18\right)$ than the Polish $\left(M_{\mathrm{j}}=3.17, \mathrm{SD}=.06\right.$ and $M_{\mathrm{pi}}=4.71$, $\mathrm{SD}=.17)$ and the South African samples $\left(M_{\mathrm{j}}=3.25, \mathrm{SD}=.07\right.$ and $\left.M_{\mathrm{pi}}=4.59, \mathrm{SD}=.18\right)$. A LSD post hoc test for differences between these countries was significant at $p<.001$ for purchase intent, at $p=.011$ between Polish and British judgements and $p=.001$ between South African and British judgements. Neither judgements nor purchase intent differed significantly between Poland and South Africa.

\section{Discussion}

Two main hypotheses were examined cross-nationally. The stereotype content hypothesis predicted greater preference for non-traditional 'paternalistic' male portrayal in advertisements as opposed to traditional 'envious' male portrayal. The match hypothesis, on the other hand, predicted greater preference for advertisement types that match pre-existing individual gender attitudes. The cross-national generalizability of these hypotheses was investigated across three countries: the UK, Poland and South Africa. These countries differ in the extent to which egalitarian norms are in operation (Zawisza et al., 2012). In particular, it was anticipated that the stereotype content hypothesis would hold cross-nationally (i.e. the stereotype similarity hypothesis) and that the strength of egalitarian norms operating in countries would restrict the applicability of the match hypothesis to those that are gender conservative only (i.e. the attitudinal differences hypothesis). These predictions were confirmed either fully or partially and the pattern of findings depends on the indicator of advertisement effectiveness used. 


\section{Stereotype content hypothesis holds across three courtiers: support for the stereotype similarity hypotheses}

Findings supported the prediction that the stereotype content hypothesis would hold across all three countries. British, Polish and South African students consistently reported more favourable feelings and judgements in response to the non-traditional 'paternalistic' advertisement than to the traditional 'envious' one. This finding is important for two reasons.

Firstly, through replicating previous findings from the United Kingdom (Zawisza, 2006; Zawisza \& Cinnirella, 2010), this result provides further support for the applicability of the SCM to advertising. Moreover, it contradicts traditional theorizing, which suggests that any departure from traditional gender stereotypes will meet with a negative response (Eagly et al., 1991; Fiske \& Stevens, 1993). From this perspective, preference should be afforded traditional Businessman portrayals over non-traditional Househusband ones, but our findings do not support this. The content of the stereotype appears to matter more than whether traditional gender stereotypes are adhered to. This may explain why previous research concerning the effectiveness of (non)gendered advertisements has produced inconsistent findings. Some of this research can be reinterpreted as a result. Debevec and Iyer (1986), for example, posited that 'novelty' plays a role in increasing the effectiveness of non-traditional advertisement strategies. Yet, it is doubtful that novelty alone is sufficient to increase their effectiveness. The SCM highlights the importance of warmth in increasing advertisement effectiveness. It suggests that non-traditional advertisements, such as the 'paternalistic' Househusband portrayal, are liked to a greater extent than traditional advertisements that rely on 'envious' stereotypes. It could, therefore, be argued that the notion of warmth better accounts for Debevec and Iyer's findings than that of novelty alone. The findings of Garst and Bodenhousen (1997) also support this argument. These authors found that non-traditional androgynous male portrayal was preferred over traditional portrayal.

Secondly, findings supported the stereotype similarity hypothesis, which predicted cross-national preference for 'paternalistic' advertising strategies over 'envious' ones. They provide evidence for the cross-national universality of the SCM (Cuddy et al., 2008, 2009; Fiske et al., 2006) and point towards its predictive strength irrespective of the degree of gender egalitarianism operating in any country. Findings also converge with those reported by other cross-national studies into gender stereotypes (Williams \& Best, 1982, 1990). The current study develops this empirical literature through examining a Polish sample, a previously neglected population in this area. In sum, our findings suggest it is not adherence to traditional stereotypes but the content of these that determines the effectiveness of gendered advertisements. Pre-existing attitudes to gender roles may, nonetheless, further influence the effectiveness of such advertisements.

\section{The match hypothesis is restricted by the strength of egalitarian norms: support for attitudinal differences hypothesis}

The role of gender attitudes in determining advertisement effectiveness was found to differ across country largely as predicted by the attitudinal differences hypothesis for purchase intent only. The match hypothesis (i.e. preference for gendered advertisements that match pre-existing individual gender attitudes) held partially and irrespective of country for feelings and judgements about the advertisements. Gender liberal individuals indeed responded more positively to the Househusband advertisement type than to the Businessman one and they were less positive about the Businessman advertisement than Traditional individuals. However, they still did not differ from Traditionals in their evaluations of the Househusband advertisement and the Traditionals still favoured the Househusband advertisement over the Businessman advertisement. It may be that Traditionals in all three countries have been motivated enough to appear non-prejudiced, and this motivation limited the predictive value of their gender attitudes. This is consistent with Aversive Racism Theory (Gaertner \& Dovidio, 1986) but awaits direct testing. However, the findings pertaining to purchase intent showed a pattern more consistent with the attitudinal differences hypothesis. Specifically, gender attitudes did not influence advertisement 
preferences in the most egalitarian country - the UK - and supported the match hypothesis partially in more conservative SA. That is, in SA, Traditionals showed higher purchase intent for the Businessman advertisement than the Househusband advertisement. In Poland, however, this pattern was reversed. Traditionals in this country favored the Househusband advertisement over the Businessman advertisement. One possible explanation is that this represents an example of overcompensation on the part of Traditionals whereby they are so concerned about appearing prejudiced that they express greater preference for the target of the prejudice (Gaertner \& Dovidio, 1986). Further studies could fruitfully examine this possibility by measuring such motivations explicitly. More research is also need to understand why the patterns differ depending on which indicator of advertisement effectiveness used despite their significant positive correlation ( $r=.16$ to $.39, p<.001$ on the current data). Overall, these findings are important for a number of reasons.

Firstly, they indirectly contribute towards existing research concerning cross-national attitudinal differences (Glick et al., 2000, 2004; Williams \& Best, 1982, 1990; Zawisza et al., 2012) through confirming the gender-conservativism of SA and the relative gender-egalitarianism of the UK. They also once again contribute towards existing empirical literature through examining a Polish sample and suggest that this country may be more egalitarian than previously thought. These findings require further examination. In particular, it would be beneficial to establish the level of gender egalitarianism required to override match tendencies.

Secondly, our findings shed light on inconsistencies in empirical literature regarding the match hypothesis (see Palan, 2001; Zawisza, 2006 for overviews). Through revealing the potential role of egalitarian norms on the relation between gender attitudes and the effectiveness of gendered advertisements, the present research suggests when gender attitudes will be less predictive of advertisement effectiveness. It is possible that studies failing to reveal advertisement type $\times$ gender attitude interaction effects (Bellizzi \& Milner, 1991; Debevec \& Iyer, 1986; Duker \& Tucker, 1977; Garst \& Bodenhausen, 1997; Whipple \& Courtney, 1980; Zawisza \& Cinnirella, 2010) were conducted in more egalitarian contexts than those that did detect such effects (Barry et al., 1985; Ford \& Latour, 1993). Indeed Debevec and Iyer (1986), as well as Bellizzi and Milner (1991), explained the lack of support for the match hypothesis in their respective studies as due to the liberal attitudes of their participants. Here this possibility was tested directly for the first time. Our findings also further suggest that methodological differences in the type of advertisement effectiveness indicator chosen (e.g. purchase intent vs. feelings or judgements) may have contributed to the inconsistencies.

\section{Directions for future research}

This study makes use of advertisements that portray male characters and examines the role of attitudes to male gender roles. A similar investigation into the effectiveness of traditional and non-traditional female portrayal and the role of female gender attitudes would be beneficial. This should seek to examine the generalisability of findings across different gender stereotypes. Existing evidence implies that the stereotype content hypothesis holds for Housewife and Businesswomen portrayals in the UK (Zawisza \& Cinnirella, 2010) and Poland (Zawisza \& Zawadzka, 2003). The inclusion of more moderate to strongly gender-conservative countries in a study of this kind would help to further determine the level of gender egalitarianism required to override match tendencies.

The predicted pattern of findings did not always surface. For example, the advertisement type main effect emerged consistently for feelings and judgements about the advertisement but not for purchase intent. This inconsistency should not necessarily be viewed as evidence against the stereotype content hypothesis. Rather, it may suggest that the variance in purchase intent may be explained by factors other than just the advertisement type - e.g. relevance of the product to the individual (e.g. Brown \& Stayman, 1992; Burke \& Edell, 1989) which was not measured here. Future research might usefully investigate this possibility.

The findings in this study are based on advertising using a low-involving product (i.e. unisex orange juice). One could argue that Househusband advertisement strategy might be more effective for product 
such as orange juice, as used in the current study, as it is a household-related product. However, in previous studies, non-traditional male characters were reported to increase the effectiveness of advertisements for various products from household-related washing-up liquid (Debevec \& Iyer, 1986) to more neutral cups of coffee and work-related personal computers (Garst \& Bodenhausen, 1997). Nonetheless, it is feasible that similar findings would not hold for advertising using a high-involving product (e.g. cars or durables). According to the Elaboration Likelihood Model (Petty \& Wegner, 1998), factors such as advertisement type and gender attitudes may serve as peripheral cues in persuasion, and as such will affect persuasive processes in conditions of low involvement only. Alternatively, in conditions of high involvement, consumers are more likely to pay attention to the real merits of the advertising message, such as the strength of arguments, and therefore simple peripheral cues will have lesser impact on their attitudes and purchase decisions. Recent research also shows that the level of product involvement may determine the relevance of the warmth and competence (of the stereotype used in the advertisement) to the advertised product and may thus affect advertisement effectiveness (Zawisza \& Pittard, 2015). These possibilities require further systematic investigation in order to establish the generalizability of the current findings across products and market contexts that vary in involvement level.

\section{Practical and theoretical implications}

The current research has two main theoretical and related practical implications. Firstly, it provides further cross-national evidence in support of the SCM (Fiske et al., 2002) and hence its universal applicability. It also supports previous research by Zawisza (2006) and Zawisza and Cinnirella (2010), not only through replicating results that demonstrate the relevance of the SCM to advertising in the UK, but also through indicating its applicability to more global advertising contexts. This research challenges the widespread conviction, based on traditional theorizing, that departure from the use of traditional gender stereotypes reduces advertising effectiveness. The content of the stereotype seems of more importance. In practical terms, this suggests that the general reluctance to portray men non-traditionally in advertising (Furnham \& Skae, 1997; Kaufman, 1999) is unjustified. Moreover, research not only shows that these portrayals trigger more positive affective and cognitive responses, but are also recalled to a better extent than traditional male portrayals (Zawisza \& Cinnirella, 2010).

Secondly, this study suggests that egalitarian norms may limit the role gendered attitudes play in predicting the effectiveness of gendered advertisements. These findings build upon previous research concerning the match hypothesis by suggesting when gender attitudes are likely to predict the effectiveness of gendered advertisements. This has practical implications. It implies that in egalitarian contexts, other gender-related variables (e.g. gender identity), which are less sensitive to egalitarian norms, could be used to predict the effectiveness of non-traditional gendered advertisements. Another possibility is to use implicit measures of gender attitudes, especially in egalitarian countries (Zawisza \& Lobban, 2015). In conclusion, it appears non-traditional 'paternalistic'male portrayal is a more effective advertisement strategy than a traditional 'envious' one across countries. Moreover, it seems that gender attitudes may determine the effectiveness of these advertisements further, especially in gender conservative countries.

\section{Notes}

1. A comparison of the key demographics is reported in Zawisza et al. (2012) - a subsample of the data is used here.

2. Attractiveness was tested in a separate pilot study ( $n=18$ students from a high school in Marlow, London: 6 men and 12 women, averaging 17 years old, the majority of whom were British -83.3\%). They evaluated the adult models in the photographs on a seven-point semantic differential scales $(-3=$ very unattractive and $3=$ very attractive). An independent $t$ test showed that the two sets of pictures did not differ in attractiveness: $M_{\mathrm{Tr}}=.9, \mathrm{SD}=1.21 \mathrm{vs}$. $M_{\mathrm{nTr}}=1.63, \mathrm{SD}=1.36, t(14)=1.59, p=.135, d=-.568$.

3. The traditional Bm1 advertisement depicted a smartly dressed man in his early 30s in an outdoor setting, standing on a busy city centre pavement and talking on a mobile phone. The Bm2 advertisement depicted another smartly dressed man in his early 30s in an office setting, standing next to his desk with a laptop on it, holding a newspaper and talking on a mobile phone. The non-traditional Hh1 advertisement portrayed a casually dressed man in his 
mid-30s in a home setting, standing next to an ironing board with a pile of clothes on it, and ironing a T-shirt. The non-traditional Hh2 advertisement portrayed the same man, in the same setting, performing the same activities. In this instance, however, he was also holding a newborn baby. Other features of the advertisements were kept constant: in all cases the men were depicted from their waist up, they were smiling, and were presented in frontal view. The heading variably read: 'Fathers/Professional men agree: until you try new X/Y orange juice you will never know what a real orange juice tastes like' The product (i.e. a glass of orange juice surrounded by sliced oranges) was positioned in the middle right section of the advertisements.

4. The pilot study showed that the orange juice received a mean score of -.78 and a modal score of 0 on the Product Gender Scale [anchored: 'feminine' (-3) and 'masculine'(3)]. It also received a mean score of 2.56 and modal score of 2 on the Product Involvement Scale [anchored: 'product requires little thought when purchasing' (1) vs. 'a lot of thought'(7)].

5. All effect size calculations for paired $t$ tests reported here were corrected for dependence between means for paired $t$ tests, using Morris and DeShon's (2002) equation 8 (calculator available at http://www.cognitiveflexibility. org/effectsize/).

\section{Disclosure statement}

No potential conflict of interest was reported by the authors.

\section{Funding}

This work was supported by the Interinstitutional funds.

\section{Notes on contributors}

Magdalena Zawisza is a senior lecturer in Psychology at Anglia Ruskin University, Cambridge. Her main research interests include consumer, gender and social psychology. She employs quantitative methodology in her research and consultancy. She is a co-editor of the International Handbook of Consumer Psychology.

Russell Luyt is head of the Department of Psychology, Social Work and Counselling at the University of Greenwich, London. His research interests lie in the social psychology of gender, and in particular, men and masculinities. He has published widely in the area, adopting both quantitative and qualitative methodologies, and well as advocating the use of mixed method research.

Anna Maria Zawadzka is an associate professor in Institute of Psychology at University of Gdańsk, Gdańsk, and head of the Department of Economic Psychology and Organizational Psychology. Her scientific interests concerns values and goals in consumer culture and the relation between them and quality of life. In recent years, she has focused especially on determinants of materialism in children and adolescents.

Jacek Buczny is an assistant professor at the University of Social Sciences and Humanities in Sopot, Poland. His expertise lies in Personality Psychology, Social Psychology and Psychometrics. His research takes positivist approach and focuses mainly on psychological aspects of self-regulation and self-control mechanisms.

\section{References}

Barry, T. E., Gilly, M. C., \& Doran, L. E. (1985). Advertising to women with different career orientation. Journal of Advertising Research, 25, 26-35.

Bellizzi, J. A., \& Milner, L. (1991). Gender positioning of a traditionally male-dominant product. Journal of Advertising Research, 31, 72-80.

Brescoll, V. L., \& Uhlmann, E. L. (2005). Attitudes toward traditional and nontraditional parents. Psychology of Women Quarterly, 29, 346-445.

Brislin, R. W. (1970). Back-translation for cross-cultural research. Journal of cross-cultural psychology, 1, $185-216$.

Brown, S. P., \& Stayman, D. M. (1992). Antecedents and consequences of attitude toward the ad: A meta-analysis. Journal of Consumer Research, 19, 34-50.

Burke, M. C., \& Edell, J. A. (1989). The impact of feelings on ad-based affect and cognition. Journal of Marketing Research, 26, 69-83.

Cuddy, A., Fiske, S. T., \& Glick, P. (2008). Warmth and competence as universal dimensions of social perception: The stereotype content model and the BIAS map. Advances in Experimental Social Psychology, 40, 61-149. 
Cuddy, A., Fiske, S. T., Kwan, V., Glick, P., Demoulin, S., Leyens, J. P., ... Ziegler, R. (2009). Stereotype content model across cultures: Towards universal similarities and some differences. British Journal of Social Psychology, 48, 1-33.

Cuddy, A., Norton, M. I., \& Fiske, S. T. (2005). This old stereotype: The pervasiveness and persistence of the elderly stereotype. Journal of Social Issues, 61, 265-283.

Debevec, K., \& Iyer, E. (1986). The influence of spokespersons in altering a product's gender image: Implications for advertising effectiveness. Journal of Advertising, 15, 12-20.

Du Plessis, E. (2005). The advertised mind: Ground-breaking insights into how our brains respond to advertising. London: Kogan Page.

Duker, J. M., \& Tucker, L. R. J. (1977). “Women's lib-ers” versus independent women: A study of preferences for women's roles in advertisements. Journal of Marketing Research, 14, 469-475.

Eagly, A. H., Mladinic, A., \& Otto, S. (1991). Are women evaluated more favorably than men? Psychology of Women Quarterly, 15, 203-216.

Eckes, T. (2002). Paternalistic and envious gender stereotypes: Testing predictions from the stereotype content model. Sex Roles, 47, 99-114.

Eisend, M. (2010). A meta-analysis of gender roles in advertising. Journal of the Academy of Marketing Science, 38, $418-440$.

Eisend, M., Plagemann, J., \& Sollwedel, J. (2014). Gender roles and humor in advertising: The occurrence of stereotyping in humorous and nonhumorous advertising and its consequences for advertising effectiveness. Journal of Advertising, 43, 256-273.

Falkenberg, S. D., Hindman, C. D., \& Masey, D. (1983). Measuring attitudes toward males in society. Paper presented at the Southeastern Psychological Association, Atlanta, GA.

Fiske, S. T., Cuddy, A., \& Glick, P. (2006). Universal dimensions of social cognition: Warmth and competence. Trends in Cognitive Sciences, 11, 77-83.

Fiske, S. T., Cuddy, A. J., Glick, P., \& Xu, J. (2002). A model of (often mixed) stereotype content: Competence and warmth respectively follow from perceived status and competition. Journal of Personality and Social Psychology, 82, 878-902.

Fiske, S. T., \& Stevens, L. E. (1993). What's so special about sex? Gender stereotyping and discrimination. In S. Oskamp \& M. Costanzo (Eds.), Gender issues in contemporary society (pp. 174-196). London: Sage.

Fiske, S. T., \& Taylor, S. (1991). Social cognition (2nd ed.). New York, NY: McGraw-Hill.

Fiske, S. T., Xu, J., Cuddy, A. J., \& Glick, P. (1999). (Dis)respecting versus (dis)liking: Status and interdependence predict ambivalent stereotypes of competence and warmth. Journal of Social Issues, 55, 473-489.

Ford, J. B., \& Latour, M. S. (1993). Differing reactions to female role portrayals in advertising. Journal of Advertising Research, 3, 43-51.

Furnham, A., \& Skae, E. (1997). Changes in the stereotypical portrayal of men and women in British television advertisements. European Psychologist, 2, 44-51.

Gaertner, S. L., \& Dovidio, J. F. (1986). The aversive form of racism. In J. F. Dovidio \& S. L. Gaertner (Eds.), Prejudice, discrimination, and racism (pp. 61-89). New York, NY: Academic Press.

Garst, J., \& Bodenhausen, G. V. (1997). Advertising's effects on men's gender role attitudes. Sex Roles, 36, 551-572.

Glick, P. (2002). Sacrificial lambs dressed in wolves' clothing: Envious prejudice, ideology, and the scapegoating of Jews. In L. S. Newman \& R. Erber (Eds.), Understanding genocide: The social psychology of the Holocaust (pp. 113-142). London: Oxford University Press.

Glick, P., Fiske, S., Mladinic, A., Saiz, J. L., Abrams, D., \& Masser, B. (2000). Beyond prejudice as simple antipathy: Hostile and benevolent sexism across cultures. Journal of Personality and Social Psychology, 79, 765-775.

Glick, P., \& Fiske, S. T. (1996). The Ambivalent Sexism Inventory: Differentiating hostile and benevolent sexism. Journal of Personality and Social Psychology, 70, 491-512.

Glick, P., \& Fiske, S. T. (1999). The ambivalence toward men inventory. Psychology of Women Quarterly, 23, 519-536.

Glick, P., Fiske, S. T., Masser, B., Manganelli, A. M., Huang, L., Castro, Y. R., ... Wells, R. (2004). Bad but bold: Ambivalent attitudes toward men predict gender inequality in 16 Nations. Journal of Personality and Social Psychology, 86, 713-728.

Iacobucci, D., Posovac, S. S., Kardes, F. R., Schneider, M. J., \& Popovich, D. L. (2015). Toward a more nuanced understanding of the statistical properties of a median split. Journal of Consumer Psychology, 25, 652-665. doi: 10.1016/j.jcps.2014.12.002

Infanger, M., \& Sczesny, S. (2015). Communion-over-agency effects on advertising effectiveness. International Journal of Advertising, 34, 285-306.

Jaffe, L. J., \& Berger, P. D. (1994). The effect of modern female role portrayals on advertising effectiveness. Journal of Advertising Research, 34, 32-41.

Judd, C. M., James-Hawkins, L., Yzerbyt, V., \& Kashima, Y. (2005). Fundamental dimensions of social judgement: Understanding the relations between judgements of competence and warmth. Journal of Personality and Social Psychology, 89, 899-913.

Kaufman, G. (1999). The portrayal of men's family roles in television commercials: Statistical data included. Sex Roles, 41, 349-458.

Kervyn, N., Fiske, S. T., \& Malone, C. (2012). Brands as intentional agents framework: How perceived intentions and ability can map brand perception. Journal of Consumer Psychology, 22, 166-176.

Lenton, A. P., Sedikides, C., \& Bruder, M. (2006, March 30). Broads and narrows: An investigation of gender stereotype structure Paper presented at the BPS New Annual Conference, Cardiff. 
Lin, M. H., Kwan, V. S. Y., Cheung, A., \& Fiske, S. T. (2005). Stereotype content model explains prejudice for an envied outgroup: Scale of anti-Asian American stereotypes. Personality and Social Psychology Bulletin, 31, 34-47.

Lipsitz Bem, S. (2000). The lenses of gender. Gdansk: Gdanskie Wydawnictwo Psychologiczne.

Martin, C. L. (1995). Stereotypes about children with traditional and nontraditional gender roles. Sex Roles, 33, $727-751$.

Morris, S. B., \& DeShon, R. P. (2002). Combining effect size estimates in meta-analysis with repeated measures and independent-groups designs. Psychological Methods, 7, 105-125.

Nelson, T. D. (2002). Psychology of prejudice. Boston, MA: Pearson Education Company.

O’Brien, M., Mistry, R., Hruda, L., Caldera, Y., \& Huston, A. (2000). Gender-role cognition in three-year-old boys and girls. Sex Roles, 42, 1007-1025.

Olson, J., Frieze, I., Wall, S., Zdaniuk, B., Ferligoj, A., Kogovšek, T., ... Makovec, M.R. (2007). Beliefs in equality for women and men as related to economic factors in Central and Eastern Europe and the United States. Sex Roles, 56, 297-308. Orth, U. R., \& Holancova, D. (2004). Men's and women's responses to sex role portrayals in advertisements. International Journal of Research in Marketing, 21, 77-88.

Palan, K. M. (2001). Gender identity in consumer behavior research: A literature review and research agenda. Academy of Marketing Science Review, Retrieved 5 March, 2004, from http://www.amsreview.org/articles/palan10-2001.pdf

Petty, R. E., Fleming, M. A., \& White, P. H. (1999). Stigmatized sources and persuasion: Prejudice as a determinant of argument scrutiny. Journal of Personality and Social Psychology, 76, 1-34.

Petty, R. E., \& Wegner, D. T. (1998). Attitude change: Multiple roles for persuasion variables. In D. T. Gilbert, S. T. Fiske, \& G. Lindzey (Eds.), The handbook of social psychology (4th ed., Vol. 1, pp. 323-390). New York, NY: McGraw-Hill.

Robila, M., \& Krishnakumar, A. (2004). The role of children in Eastern European families. Children and Society, $18,30-41$.

Sandnabba, N. K., \& Ahlberg, C. (1999). Parents' attitudes and expectations about children's cross-gender behavior. Sex Roles, 40, 249-263.

Sherif, M., \& Hovland, C. I. (1961). Social Judgement. New Haven, CT: Yale University Press.

Swim, J. K., Aikin, K. J., Hall, W. S., \& Hunter, B. A. (1995). Sexism and racism: Old-fashioned and modern prejudices. Journal of Personality and Social Psychology, 68, 199-214.

Swim, K. J., Mallet, R., \& Russo-Devosa, Y. (2005). Judgments of sexism: A comparison of the subtlety of sexism measures and sources of variability in judgments of sexism. Psychology of Women Quarterly, 29, 406-411.

Tougas, F., Brown, R., Beaton, A. M., \& Joly, S. (1995). Neosexism: Plus ça change, plus c'est pareil. Personality and Social Psychology Bulletin, 21, 842-849.

Whipple, T. W., \& Courtney, A. E. (1980). How to portray women in TV commercials. Journal of Advertising Research, 20, 53-59.

Williams, J. E., \& Best, D. L. (1982). Measuring sex stereotypes: Athirty-nation study. Beverly Hills, CA: Sage.

Williams, J. E., \& Best, D. L. (1990). Measuring sex stereotypes: A multination study. Beverly Hills, CA: Sage.

Williams, J. E., Satterwhite, R. C., \& Best, D. L.(1999). Pancultural gender stereotypes revisited: The five factor model. Sex Roles, 40, 513-525.

Wolin, L. D. (2003). Gender issues in advertising. Journal of Advertising Research, 43, 111-130.

Worth, L. T., Smith, J., \& Mackie, D. M. (1992). Gender schematicity and preference for gender-typed products. Psychology and Marketing, 9, 17-30.

Zawisza, M. (2006). The effectiveness of advertisements which follow or break traditional gender stereotypes (Unpublished doctoral dissertation). Royal Holloway, University of London, London.

Zawisza, M., \& Cinnirella, M. (2010). What matters more: Breaking tradition or stereotype content? Envious and paternalistic gender stereotypes and advertising effectiveness. Journal of Applied Social Psychology, 40, 1767-1797.

Zawisza, M., \& Lobban, R. (2015). Implicit and explicit gender attitudes as predictors of the effectiveness of non-traditionally gendered advertisements. International Journal of Consumer Research, 3, 34-55.

Zawisza, M., Luyt, R., \& Zawadzka, A. (2012). Ambivalence toward men: Comparing sexism among Polish, South African and British university students. Sex Roles, 66, 453-467.

Zawisza, M., \& Pittard, C. (2015). When do warmth and competence sell best? The "golden quadrant" shifts as a function of congruity with the product type, targets' individual differences, and advertising appeal type. Basic and Applied Social Psychology, 37, 131-141.

Zawisza, M., \& Zawadzka, A. M. (2003). The effectiveness of advertisements that use or break gender stereotypes. Nowiny Psychologiczne, 3, 63-80. 